\title{
RELAÇÕES EDUCACIONAIS: COMPORTAMENTOS DO PROFESSOR DE INGLÊS QUE AFETAM A MOTIVAÇÃO DO ALUNO
}

\author{
Girlane Moura HICKMANN ${ }^{1}$
}

Suzane Schmidlin LOHR ${ }^{2}$

RESUMO: Este artigo é um recorte de uma pesquisa realizada em Curitiba (PR) com 82 alunos e quatro professores de uma escola de línguas ligada a uma universidade publica federal. Partiu-se do pressuposto de que os comportamentos dos professores, ao ministrar suas aulas, poderiam influenciar positiva ou negativamente em algumas variáveis motivacionais dos alunos durante as aulas. O estudo teve como objetivo avaliar o estado e as metas motivacionais do aprendiz e relacionar esses elementos com a forma como os professores conduzem suas aulas. Os dados foram levantados através de entrevistas, aplicação de questionários e da observação direta dos comportamentos emitidos em sala de aula. As análises estatísticas dos dados feitas através dos testes não paramétricos de Kruskal-Wallis e Tukey apontaram para os seguintes resultados: 1) Quanto maior era a responsividade do professor maiores eram a Atitude positiva dos alunos em relação ao curso e a Adoção de Metas de Aprendizagem Orientadas tanto para o Desempenho Pessoal como pelo Meio; 2) Quanto mais estratégias aversivas o professor usava em sala de aula maior era a Adoção de Metas de Aprendizagem Orientadas para o Desempenho Pessoal; 3) Quanto maior é a Exigência e o Controle Aversivo, mais ansioso ficou o aluno.

PALAVRAS-CHAVE: Aprendizagem de língua inglesa. Motivação. Ansiedade. Interação professor - aluno. Escola de línguas.

\section{Introdução}

Este artigo analisa comportamentos de professores que podem afetar nas atitudes e na ansiedade dos alunos frente ao estudo do idioma inglês. Os dados que serão discorridos no escopo deste trabalho fazem parte de uma pesquisa empírica realizada em Curitiba, com 82 alunos e 4 professores de um Centro de Línguas ligado a uma universidade pública, sendo a participação nos cursos aberta à comunidade interna e externa à universidade. O Centro onde a pesquisa foi realizada é essencialmente voltado à formação profissional e continuada tanto de alunos da graduação como de professores já formados com ou sem pós-graduação. A metodologia adotada pela escola para ensinar a Língua Inglesa é a Abordagem Comunicativa ${ }^{3}$. A escola oferta 23 idiomas nas modalidades Intensivo e Extensivo, para alunos acima de 17 anos, a partir do nível

\footnotetext{
${ }^{1}$ Pesquisadora do processo de ensino-aprendizagem de idiomas, interações professor/aluno, estilos de liderança de educadores e motivação para aprendizagem. Mestre em Educação. UFPR - Universidade Federal do Paraná. Curitiba - PR - Brasil. 80.060-000 - girlanehickmann@ gmail.com

${ }^{2}$ UFPR - Universidade Federal do Paraná - Departamento de Teorias e Fundamentos da Educação. Curitiba - PR - Brasil. 80.060-000 - lohr@ superig.com.br

${ }^{3}$ Hipótese para aprendizagem baseada na função da língua e não na sua forma.
} 
básico 1. Na data da coleta de $\operatorname{dados}^{4}$ o centro possuía 3.256 alunos matriculados, dos quais 887 estudavam a Língua Inglesa.

\section{Relações educacionais}

Para a construção do arcabouço teórico sobre as relações educacionais e os comportamentos do professor de inglês que afetam a motivação do aluno, empreendeuse pesquisa bibliográfica cujo retorno foi de 43.083 artigos. O levantamento foi realizado no período de 2010 a 2015, nas Bases de Dados do ERIC, SciELO, PsycINFO e CAPES, com os seguintes descritores: estilos de liderança de professores, estilos parentais, motivação, ansiedade, autoestima, interação professor-aluno, relação professor - aluno, afetividade, relações educacionais, correção de erros na Língua Inglesa, teachers' teaching styles (estilos de ensino de professores), teachers' leadership styles (estilos de liderança de professores), motivational strategies (estratégias motivacionais), motivated classroom behavior (comportamento motivado em sala de aula), error correction in language learning (correção de erro na aprendizagem de línguas), practices of English teachers (práticas de professores de inglês), affect (afeto), language Learning (aprendizagem da língua), Language acquisition (aquisição da língua).

O professor de línguas ao se deparar com algumas dificuldades de aprendizagem dos alunos durante as aulas, entre outras medidas, pode recorrer à literatura na busca por respostas que o ajudem a suprir não só as carências individuais de cada aluno, mas também atender a turma como um todo. Ele busca por dispositivos de aperfeiçoamento que lhe possibilitem aprofundar em leituras sobre abordagens de ensino-aprendizagem de línguas, interação professor-aluno, estratégias de ensino e motivação para aprender (MOREIRA; OLIVEIRA, 2013). A busca se torna mais complexa, quando remete a variáveis emocionais do educando e do professor.

Mouraes, Brito e Teixeira (2014, p.11) ao analisarem o processo de ensino aprendizagem, destacam que "É prioridade para o futuro que o sujeito desenvolva sua potencialidade, suas habilidades mentais e que nas suas ações demostrem seus valores e propiciem mudanças de atitudes.” Segundo Aceituno, Amate e Campos (2012, p.87, tradução nossa):

\footnotetext{
${ }^{4}$ Parte da dissertação de Mestrado em Interação Professor/aluno na Aprendizagem de Língua Inglesa: motivação para aprender na Universidade Federal do Paraná (2015).
} 
[...] temos que conseguir que o ensino seja uma mistura de tradição e inovação para garantir um progresso educacional adequado dos alunos/as, de modo que a aprendizagem não resulte em algo monótono e chato, mas ao contrário, possam aprender através de novas e variadas atividades, exercícios dinâmicos, trabalho diário, esforço, experimentação e diversão.

Conhecer o clima educacional assim como os fatores que contribuam para a motivação do aprendiz e diminuam as possíveis dificuldades enfrentadas por eles no decorrer do curso, pode ajudar os professores a refletirem sobre comportamentos que afetam positivamente ou negativamente nas atitudes dos alunos.

Educando e aprendiz expressam suas emoções de variadas formas e elas podem vir a facilitar ou dificultar o processo de ensino-aprendizagem de uma segunda língua (OKAGAKI; STERNBERG, 1993). Dessa forma, entender a influência de fatores afetivos no desempenho do aluno que deseja aprender inglês poderá ajudar o professor a planejar ações que contribuam para um aprendizado mais efetivo. Bzuneck, Megliato e Rufini (2013) pressupõe que emoções como prazer, orgulho e satisfação estão presentes nas atividades de aprendizagem, resultando dessa forma no engajamento emocional do aprendiz. Todavia, o “[...] oposto consiste na vivência de emoções negativas, como tédio, desinteresse, frustração e raiva, tristeza, ansiedade, vergonha e autorrecriminação.” (BZUNECK; MEGLIATO; RUFINI 2013, p.153). Segundo Pellerin (2005) as escolas que apresentam os melhores resultados dos alunos, são aquelas que o professor combina responsividade com demandas acadêmicas e disciplinares.

Há muita variação na forma de ensinar de cada professor e maneiras mais efetivas do que outras para proporcionar ganhos aos alunos (BATISTA; WEBER, 2012). Além de proporcionar um ambiente que extrapole o ensino de conteúdos, o professor precisa estar atento aos seus próprios sentimentos e aos de seus alunos, pois a partir deles afloram ações que podem ir ao encontro de ou de encontro às expectativas do aprendiz (DINIZ; KOLLER, 2010). O professor que anseia incentivar os alunos a participarem durante as atividades propostas precisa estar atento não só aos materiais e metodologias adotadas em sala, mas também aos sinais de ansiedade e desconforto manifestados pelos alunos (MOREIRA; MEDEIROS, 2007).

Ao ministrar suas aulas, o professor emite uma variedade de comportamentos desenvolvidos em sua história de aprendizagem e que ele julga serem mais eficazes para atingir os objetivos traçados durante o planejamento de aula. As notas finais referentes 
ao desempenho de cada aluno ao terminar o curso, constitui uma das fontes para medir se as metas iniciais foram atingidas. Todavia, faz-se necessário olhar além dos boletins de notas dos alunos para entender e aperfeiçoar o processo de ensino-aprendizagem de idiomas.

Se considerarmos, como afirma Skinner (1991, p.55) que "[...] o ambiente modela e mantem repertórios de comportamento, mas também serve como ocasião para que o comportamento ocorra [...]", perceberemos que o professor que não recebe feedbacks sistemáticos quanto às suas ações, recorrerá novamente às mesmas classes de comportamentos, repetindo por vezes estratégias que são improdutivas. Alguns comportamentos emitidos pelos alunos durante as aulas, se adequadamente observados e identificados, podem fornecer pistas riquíssimas que venham a contribuir para o ajuste das aulas ou mesmo para que o professor possa aprimorar sua forma de condução das mesmas.

Para que o professor possa programar mudanças no seu fazer, focando no bem estar e na potencialização do aprendizado dos educandos sob a sua responsabilidade muitas vezes necessita de ferramentas auxiliares efetivas no desenvolvimento de suas habilidades em prol do aprendizado do aluno. Portanto, compartilhar conhecimentos, discutir o que funciona ou não em sala de aula e promover feedbacks positivos que levem em consideração a competência do aprendiz e sua progressiva performance em sala de aula, poderá abrir caminhos para uma ação-reflexão-ação sobre as estratégias, metodologias de ensino e manejo de sala de aula, contribuindo para que o professor desenvolva cada vez manejo mais eficiente (SILVA; RODRIGUES; PINHEIRO NETO, 2010).

Archer, Kerr e Pianta (2014) enfatizam que é preciso receber feedbacks sobre nossas ações e esforços para que possamos fazer bem o que deveríamos fazer de forma diferente. Para eles será difícil melhorar o ensino e aprendizagem se os professores não receberem um feedback de qualidade. Os autores defendem que o feedback seja sistematizado na escola e não apenas fruto do exercício do professor em encontrar pistas nas respostas dos alunos às atividades propostas, para delas deduzir o que é produtivo ou não para a turma.

Algumas estratégias utilizadas por professores em sala de aula podem gerar respostas de ansiedade por parte dos alunos. O estado ansioso e os comportamentos de esquiva de tarefa podem estar relacionados com os esforços do aprendiz de fugir de situações que facilitem comparações desvantajosas com colegas de classe ou rejeição e 
desaprovação da turma ou do professor (SKINNER, 1969; WENTZEL, 1999). Segundo Wentzel (1999) levar para a sala de aula atividades que ofereçam oportunidades para a criatividade e participação pode prevenir sensações de rejeição ou desaprovação por parte dos alunos. Alunos mais confiantes tendem a controlar melhor suas emoções e atitudes e se sentem menos ansiosos durante as produções orais e escritas. De acordo com Skinner e Zimmer-Gembeck (2011, p.39, tradução nossa) os alunos mais confiantes:

[...] são mais propensos a acreditar que serão efetivos em situações de estresse e, assim, avaliam os eventos negativos como desafios ao invés de ameaças. Eles encaram as tarefas com concentração e vigor, quebrando-as em partes sequenciais gerenciáveis, e empregam uma variedade de estratégias alternativas. Eles procuram por oportunidades de ação enquanto os eventos se desenrolam, e mantém o foco na resolução de problemas. Eles mantem o acesso aos seus recursos cognitivos e assim, apresentam desempenho próximo à sua capacidade máxima. Eles se mostram flexíveis e criativos na resolução de problemas e procuram por ajuda quando precisam.

\section{Objetivo da pesquisa}

O estudo teve como objetivo principal avaliar o estado e as metas motivacionais do aprendiz e relacionar esses elementos com a forma como os professores de inglês conduzem suas aulas.

\section{Metodologia}

A instituição cujos dados foram coletados oferece os cursos na modalidade Intensivo e Extensivo e foram considerados para a discussão dos resultados os dados obtidos dos participantes do curso da modalidade Extensivo apenas, a saber: quatro professoras e 82 alunos. Todos os participantes possuíam mais de dezoito anos e manifestaram espontaneamente interesse em participar da pesquisa. Os alunos eram de ambos os sexos. Só professoras manifestaram interesse em contribuir com a pesquisa, embora houvesse professores atuando na escola de idiomas.

Para coleta de dados com os alunos foram utilizados seis instrumentos, mas o presente trabalho descreve um recorte relativo aos dados de dois deles, a saber, os questionários de Estado Motivacional e de Metas Motivacionais (GUILLOTEAUX; DÖRNYEI, 2008). Ambos foram traduzidos do inglês para o português e as respostas eram registradas em um escala Likert que pontuou 1 (não concordo de forma alguma), 2 (não concordo), 3 (concordo parcialmente), 4 (concordo) e 5 (concordo plenamente). $\mathrm{O}$ 
Questionário de Estado Motivacional possui 18 questões e avalia: Atitudes em relação ao Curso, Autoconfiança Linguística e Ansiedade em sala de aula de L2 ${ }^{5}$. O questionário de Metas Motivacionais é composto por 20 perguntas e avalia: Adoção de Metas de Aprendizagem Orientadas pelo Meio, Adoção de Metas de Aprendizagem Orientadas para o Desempenho Pessoal, Esquiva de tarefa, Estrutura de Meta para Desempenho em Sala de Aula, Estrutura de Meta para Competência em Sala de Aula.

Já os dados coletados juntamente aos professores foram decorrentes do uso de quatro instrumentos, sendo que apenas um deles, a Classes de Comportamento Referente ao Professor - FCCRP faz parte das análises do presente artigo.

Para que se obtivessem as categorias comportamentais mais frequentemente utilizadas pelos professores em sala de aula, o comportamento de cada professor foi alvo de três observações cursivas, com duração aproximada de 45 minutos cada e que foram desenvolvidas em seis turmas de alunos matriculados na modalidade de curso Intensivo. Estas observações serviram como base para a construção de 13 Classes de Comportamento Referente ao Professor - FCCRP. Para analisar a fidedignidade dos registros de evento e das categorias construídas, antes de iniciar os levantamentos para a pesquisa propriamente dita, fizeram-se registros por dois observadores independentes, utilizando a FCCRP. O grau de fidedignidade foi de 93,72\%, atestando que o instrumento era adequado para observação dos professores. A construção da Ficha seguiu o modelo de definição de comportamentos do MOLT - Motivational Orientation of Language Teaching (GUILLOTEUX; DORNEY, 2008).

A partir deste ponto, os comportamentos dos professores foram registrados no formato de registro de eventos. Nove turmas, cinco delas pertencentes ao curso Intensivo e quatro do Extensivo, foram acompanhadas com os registros de evento.

Os dados foram coletados em três etapas, duas delas no Curso intensivo de férias e uma no Extensivo e todas elas respeitaram as fases documentais do projeto, na qual os participantes assinaram o Termo de Consentimento Livre e Esclarecido - TCLE. A pesquisa se adequou aos princípios e normas estabelecidos na Resolução 466/2012, pelo Conselho Nacional de Saúde - CNS, para pesquisas com seres humanos, (BRASIL, 2012), sendo submetido e aprovado por Comitê de Ética em Pesquisa, sob o parecer Consubstanciado de número 667.167.

${ }^{5}$ Segunda língua. 
Os instrumentos utilizados, o número de participantes e de questões e o tempo de observação, que fazem parte desse recorte, podem ser visualizados no Gráfico 1.

\section{Gráfico 1 - Instrumentos utilizados}

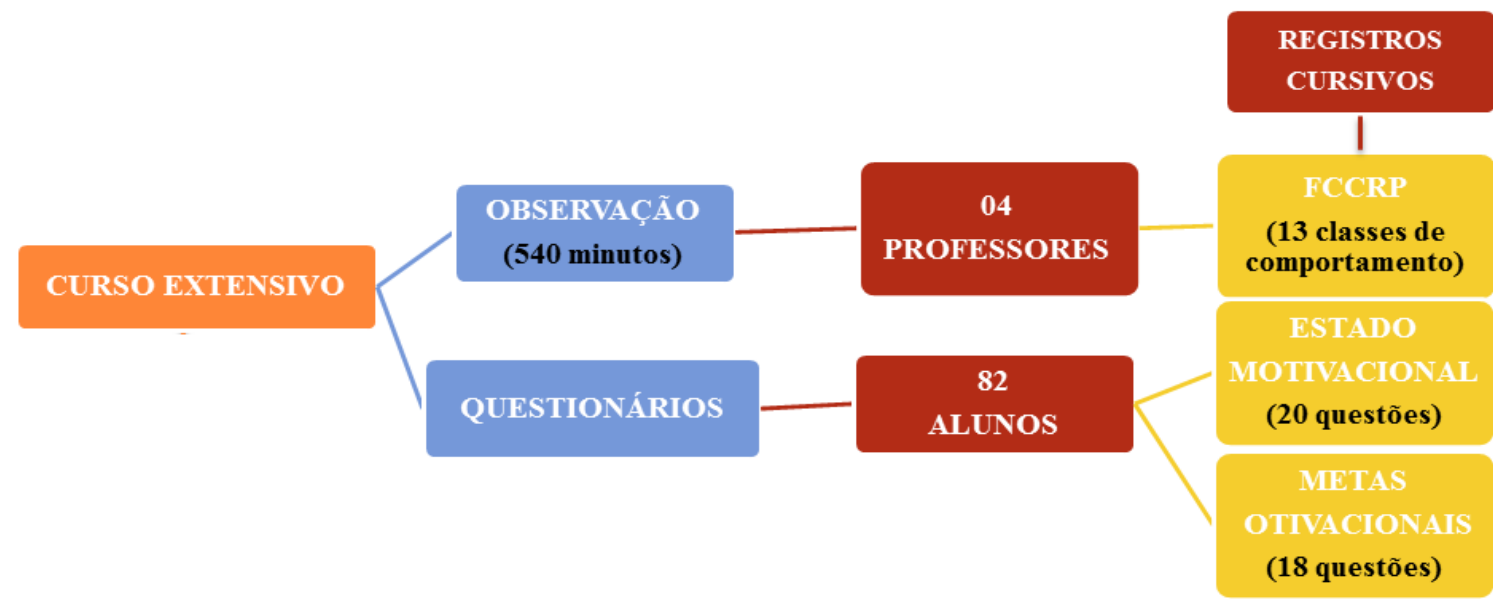

Fonte: Elaboração própria.

\section{Resultados}

A folha de registro FCCRP contemplava 13 classes de comportamentos: nove ligados à classe promoção de motivação e quatro a categorias que afastam a motivação. Cinco categorias presentes na FCCRP não foram pontuadas nas diversas observações realizadas ou o foram em índice muito baixo, de forma que se optou por não incluí-las no artigo, passando o mesmo a contemplar apenas as oito categorias que receberam maior número de pontuações.

A operacionalização das classes de comportamento de professores pode ser visualizada na Tabela 1. 


\section{Quadro 1 - categorias para observação do comportamento do professor}

\begin{tabular}{|c|c|}
\hline 1. Ponte - PNT & $\begin{array}{l}\text { O período de tempo no qual o professor fornece estratégias } \\
\text { e/ou modelos escritos ou orais adequados, de modo a } \\
\text { aumentar as chances dos alunos completarem uma atividade } \\
\text { com sucesso. Por exemplo, o professor descreve verbalmente } \\
\text { ou de forma escrita o processo para solução da atividade ao } \\
\text { mesmo tempo em que faz demonstrações, lembra aos alunos } \\
\text { de conhecimento ou habilidades já trabalhados que irão ajudá- } \\
\text { los a completar a tarefa, ou faz na sala, ou trabalha uma lista } \\
\text { de estratégias para a solução de uma tarefa. }\end{array}$ \\
\hline $\begin{array}{l}\text { 2. Promover A Cooperação - } \\
\text { PCO }\end{array}$ & $\begin{array}{l}\text { O período de tempo no qual o professor configura uma tarefa } \\
\text { de aprendizagem que para a sua solução requer a participação } \\
\text { de outro colega, ou expressamente incentiva os alunos a } \\
\text { ajudarem uns aos outros e/ou oferece-lhes sugestões sobre a } \\
\text { melhor forma de fazer isso. }\end{array}$ \\
\hline $\begin{array}{l}\text { 3.Promover Autocorreção Ou } \\
\text { Correção De Atividades Com O } \\
\text { Colega - PCR }\end{array}$ & $\begin{array}{l}\text { O período de tempo no qual o professor incentiva os alunos } \\
\text { a analisar seus trabalhos, revendo o próprio trabalho ou o } \\
\text { trabalho dos seus pares, possibilitando a correção de erros. }\end{array}$ \\
\hline $\begin{array}{l}\text { 4. Elogiar O Trabalho Dos Alunos } \\
\text { - EL }\end{array}$ & $\begin{array}{l}\text { Período de tempo no qual o professor oferece pelo menos um } \\
\text { exemplo de elogio por esforço ou conquista - que seja sincero, } \\
\text { específico e compatível com a realização do aluno. Ou seja, } \\
\text { não é o professor simplesmente dizer "bom trabalho!", mas } \\
\text { especifica o que é bom sobre o trabalho. }\end{array}$ \\
\hline $\begin{array}{l}\text { 5. Incentivar O Aluno A Tentar } \\
\text { Uma Resposta, Sem Se Preocupar } \\
\text { Com Haver Uma Resposta } \\
\text { Correta - IN }\end{array}$ & $\begin{array}{l}\text { Período de tempo no qual o professor incentiva o aluno a } \\
\text { tentar uma resposta, sem se preocupar com a correta produção } \\
\text { do aluno. }\end{array}$ \\
\hline $\begin{array}{l}\text { 6. Circular Entre Os Alunos Com } \\
\text { Interação - CEAI }\end{array}$ & $\begin{array}{l}\text { Período de tempo no qual o professor circula entre os alunos } \\
\text { interagindo com eles e corrigindo a produção oral ou escrita. }\end{array}$ \\
\hline $\begin{array}{l}\text { 7. Criticar Resposta Dada Pelo } \\
\text { Aluno-CR }\end{array}$ & $\begin{array}{l}\text { Período de tempo no qual o professor critica a produção do } \\
\text { aluno, preocupando-se mais com o desempenho do que com a } \\
\text { tentativa de acerto do aluno. }\end{array}$ \\
\hline 8. Denotando Passividade - DP & $\begin{array}{l}\text { Período de tempo no qual o professor está simplesmente na } \\
\text { sala sem estabelecer relação positiva ou negativa com os } \\
\text { alunos. Excluem-se dessas categorias de comportamentos as } \\
\text { atividades que exigem do professor a não interação com o } \\
\text { aluno como as atividades de listening e chamada silenciosa. }\end{array}$ \\
\hline
\end{tabular}

Fonte: Elaboração própria.

O comparativo da emissão de comportamentos em cada uma das categorias de observação, por parte das professoras pesquisadas, pode ser visualizado na Tabela 1. Para manter o anonimato das professoras, o nome de cada uma foi substituído pelo nome de uma poetisa da literatura inglesa. 
Tabela 1 - Comparativo do número de comportamentos emitidos pelas professoras

\begin{tabular}{|c|c|c|c|c|c|c|c|c|c|c|}
\hline \multirow{2}{*}{\multicolumn{2}{|c|}{$\begin{array}{c}\text { PROFESSOR } \\
\text { TURMA }\end{array}$}} & \multicolumn{2}{|c|}{$\begin{array}{l}\text { ANNE } \\
\text { SEXTON }\end{array}$} & \multicolumn{2}{|c|}{$\begin{array}{c}\text { ELIZABETH } \\
\text { BISHOP }\end{array}$} & \multicolumn{2}{|c|}{$\begin{array}{c}\text { AMY } \\
\text { CLAMPITT }\end{array}$} & \multicolumn{2}{|c|}{$\begin{array}{c}\text { EMILY } \\
\text { DICKINSON }\end{array}$} & \multirow[t]{2}{*}{ TOTAL } \\
\hline & & I & $\mathrm{H}$ & E & $\mathrm{D}$ & $\mathrm{G}$ & $\mathrm{F}$ & B & $\mathrm{C}$ & \\
\hline \multirow{8}{*}{ 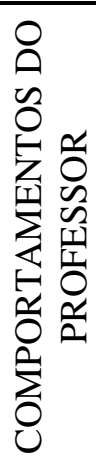 } & 1. PNT & 9 & 10,33 & 6,33 & 4 & 6,67 & 5,33 & 8 & 9,33 & 58,99 \\
\hline & 2. $\mathrm{PCO}$ & 5 & 3,33 & 11 & 1 & 0,33 & 0,67 & 9 & 5,67 & 36 \\
\hline & 3 PCR & 2 & 2,33 & 4,67 & 0,33 & 0,67 & 0,33 & 1,67 & 2,67 & 14,67 \\
\hline & 4. EL & 1,33 & 2,33 & 2,33 & 2 & 2 & 0,67 & 2 & 2,33 & 14,99 \\
\hline & 5. IN & 12 & 6 & 6,67 & 9,33 & 6 & 7 & 14,67 & 12 & 73,67 \\
\hline & 6. CEAI & 2 & 3,67 & 8,67 & 3,67 & 5,33 & 0,67 & 3,67 & 1,67 & 29,35 \\
\hline & 7. CR & 0 & 0 & 1,67 & 2,33 & 0 & 0 & 0 & 0 & 4 \\
\hline & 8. DP & 0,67 & 2,67 & 1,67 & 1,67 & 5,67 & 4,67 & 2,33 & 5,67 & 25,02 \\
\hline
\end{tabular}

NOTA: PNT = ponte; $\mathrm{PCO}=$ promover a cooperação; $\mathrm{PCR}=$ promover autocorreção ou correção de atividades com o colega; $\mathrm{EL}=$ elogiar o trabalho dos alunos; $\mathrm{IN}=$ incentivar o aluno a tentar uma resposta, sem se preocupar com haver uma resposta correta; CEAI = circular entre os alunos com interação; $\mathrm{CR}=$ criticar resposta dada pelo aluno; $\mathrm{DP}=$ denotando passividade.

Fonte: Elaboração própria.

As classes de comportamentos que podem promover a motivação dos alunos mais emitidos pelas professoras, durantes as aulas, foram: incentivar o aluno a tentar uma resposta sem se preocupar com haver uma resposta correta ( $\mathrm{IN}=73,67$ ), ponte $(\mathrm{PNT}=58,99)$, promover a cooperação $(\mathrm{PCO}=36)$ e circular entre os alunos com interação $(\mathrm{CEAI}=29,35)$.

As categorias que interferem negativamente no processo de aprendizado dos alunos prejudicando a motivação do aprendiz mais frequentemente utilizadas pelas professoras foram: denotar passividade $(\mathrm{DP}=25,02)$ e criticar resposta dada pelo aluno $(\mathrm{CR}=4)$.

Elogiar o desempenho dos alunos pode contribuir para que o aluno se engaje na atividade que vem desenvolvendo, aumentando sua participação no que obteve reconhecimento. Infelizmente, esta foi uma classe de comportamentos pouco frequente por parte das quatro professoras $(E L=14,99)$. Outra categoria que foi manifestada em baixa frequência, foi a de promover autocorreção ou correção de atividades com o colega (PCR=14,67). Comparando a frequência de comportamentos emitidos pelas quatro professoras em suas respectivas turmas (TABELA 1), foi possível perceber que as professoras Amy Clampitt e Elizabeth Bishop foram as que menos promoveram cooperação e autocorreção ou correção de atividades com o colega (turmas D e F). É provável que essas professoras tenham adotado métodos de construção individual de conhecimento nestas turmas. 
As únicas turmas cuja professora criticou as respostas dadas pelos alunos em sala de aula foram as Turmas D $(2,33)$ e E $(1,67)$, ambas da professora Elizabeth Bishop. Entretanto a turma D $(4,0)$ foi a que menos recebeu do professor estratégias escritas ou orais que poderiam elevar as chances dos alunos completarem uma atividade com sucesso, representada especialmente pelo uso de estratégias de Ponte. Supõe-se que os alunos, por não terem recebido modelos adequados e necessários para ajuda-los na produção, cometiam mais erros e dessa forma, tinham suas respostas mais frequentemente criticadas pela professora.

Por outro lado as professoras Emily Dickinson (turma B - 14,67 e C - 12,0) e Anne Sexton (turma I - 12,0) foram as que mais incentivaram os alunos a tentar uma resposta, sem se preocupar com haver uma resposta correta - IN. Também foram essas professoras as que mais demonstraram lembrar os alunos de habilidades e conhecimentos já trabalhados em sala de aula (Ponte), o que os ajudaria a completar as tarefas com sucesso.

O questionário sobre o Estado Motivacional do Aluno, respondido pelos alunos, avaliou as Atitudes dos mesmos em relação ao curso, Autoconfiança linguística (percepção de sua capacidade de lidar com aprendizagem da língua e em alcançar os objetivos desejados em termos de proficiência) e Ansiedade em sala de aula (nível geral de ansiedade quando têm que usar o idioma em sua classe atual). Os dados obtidos podem ser visualizados na Tabela 2:

Tabela 2 - Estado motivacional do aluno

\begin{tabular}{l|l|l|l}
\hline Professor & $\bar{g}$ & Pontuação parcial & Classificação \\
\hline
\end{tabular}




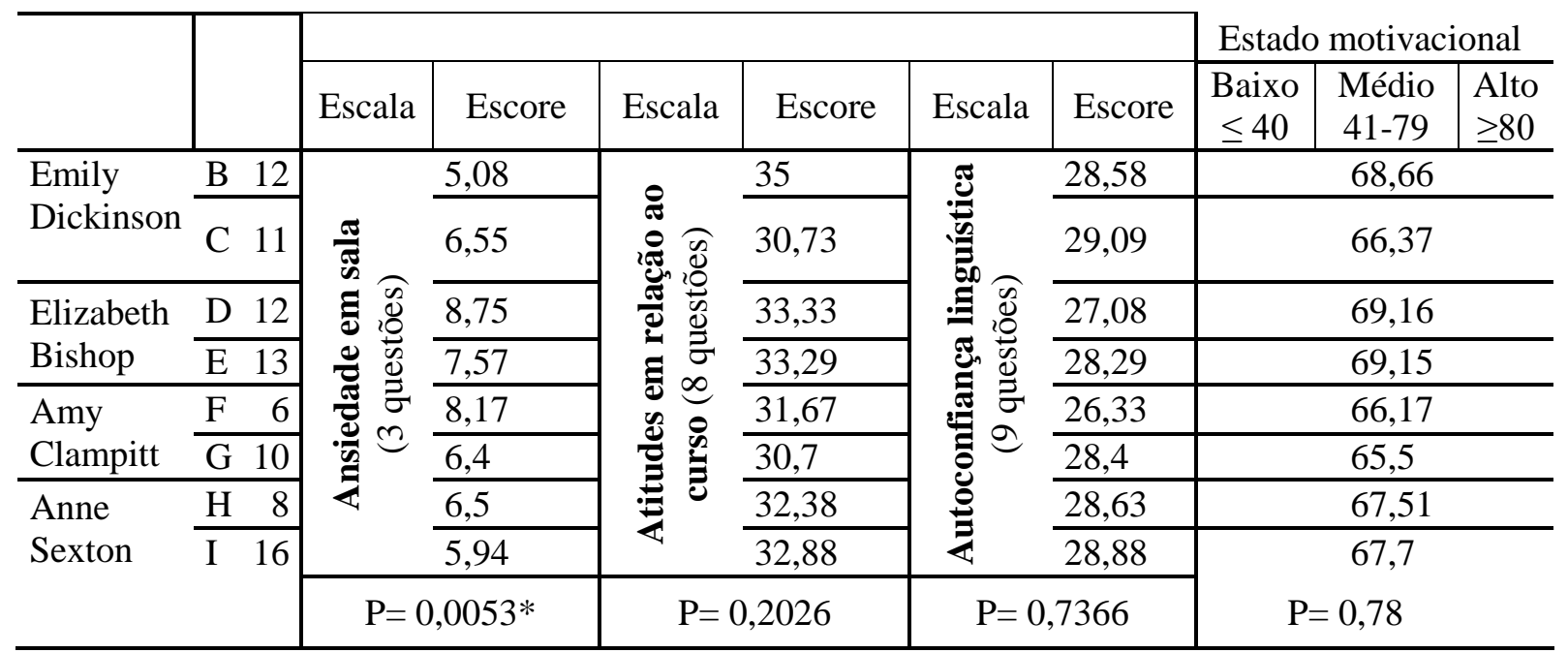

NOTA: Não houve diferença significativa entre as turmas quanto ao estado motivacional, segundo o teste de Kruskal-Wallis ( $\mathrm{p}=0,78)$.

Fonte: Elaboração própria.

A análise estatística dos dados através do teste de Kruskal-Wallis demonstrou não haver diferença significativa entre os grupos quanto ao Estado Motivacional geral do aluno $(\mathrm{p}=0,78)$. Todas as turmas pesquisadas apresentaram um Estado Motivacional Médio.

Todavia na subescala Ansiedade a diferença entre turmas mostrou significância estatística quando submetida ao mesmo teste $(\mathrm{p}=0,0053)$. Foi aplicado o Teste de Tukey para verificar quais das turmas eram significativamente diferentes umas das outras. Na subescala Ansiedade, constatou-se haver diferenças entre as turmas B e F $(\mathrm{p}=0,003)$ e $\mathrm{B}$ e $\mathrm{D}(\mathrm{p}=0,004)$. Percebe-se também que as turmas $\mathrm{D}$ da professora Elizabeth Bishop $(8,75)$ e F da Amy Clampitt $(8,17)$ apresentaram os maiores escores para ansiedade. Infere-se desse dado ter havido algum desconforto dos alunos quando solicitados a participar das atividades de sala de aula nas turmas das referidas professoras. Por outro lado as turmas B, Emily Dickinson $(5,08)$ e I, Anne Sexton $(5,94)$, foram as que apresentaram os menores escores para ansiedade. O discurso de uma das entrevistadas da professora Emily Dickinson indica o possível motivo do baixo escore para essa variável motivacional; "Eu acho que ela deixa... eu me sinto assim, segura pra arriscar, pra tentar falar as coisas porque eu não sinto assim nem um tipo de constrangimento". (Entrevistada 2, turma C).

O questionário sobre Metas Motivacionais avaliou tanto as práticas pedagógicas utilizadas pelos professores em suas salas de aula como as orientações que os alunos perseguem em contextos de realização das atividades. 
As cinco subescalas deste instrumento avaliam: a) Estrutura de meta para competência em sala de aula - Ênfase dada pelo professor à competência do aluno; b)Estrutura de meta para desempenho em sala de aula - Forte ênfase dada pelo professor às respostas exatas dadas pelos alunos; c)Adoção de metas de aprendizagem orientadas pelo meio - Nelas o aluno busca realizar bem uma tarefa, com intuito de agradar aos pais, professores ou chefes; d)Adoção de metas de aprendizagem orientadas para o desempenho pessoal - $\mathrm{O}$ foco do ensino está em alunos supostamente melhores ou mais espertos do que os outros; e)Esquiva de tarefa - Alunos que evitam a sensação de ser pressionados, constrangidos ou forçados a produzir algo.

Os dados obtidos podem ser visualizados na Tabela 3:

Tabela 3 - Metas motivacionais

\begin{tabular}{|c|c|c|c|c|c|c|c|c|c|c|c|c|c|c|}
\hline \multirow{2}{*}{ 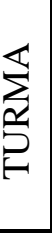 } & \multirow[t]{2}{*}{$=$} & \multicolumn{10}{|c|}{ PONTUAÇÃO PARCIAL } & \multicolumn{3}{|c|}{$\begin{array}{c}\text { CLASSIFICAÇÃO } \\
\text { METAS } \\
\text { MOTIVACIONAIS }\end{array}$} \\
\hline & & SE & $\mathrm{E}$ & SE & E & SE & E & SE & E & SE & E & \begin{tabular}{|c|} 
\\
$\leq 36$ \\
\end{tabular} & \begin{tabular}{|c|}
$\mathrm{M}$ \\
$37-71$ \\
\end{tabular} & $\begin{array}{c}\text { A } \\
\geq 72 \\
\end{array}$ \\
\hline B & 12 & \multirow{8}{*}{ 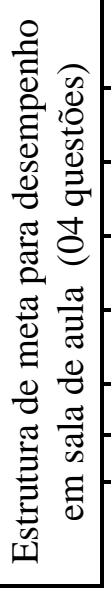 } & & \multirow{8}{*}{ 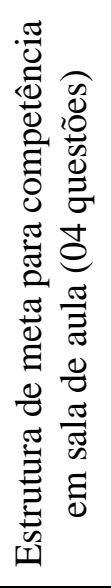 } & 18,17 & \multirow{8}{*}{ 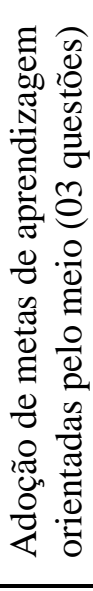 } & 4,17 & \multirow{8}{*}{ 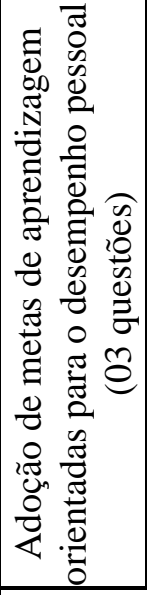 } & 5,58 & \multirow{8}{*}{ 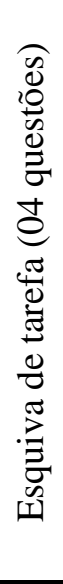 } & 6,42 & & 42,92 & \\
\hline $\mathrm{C}$ & 11 & & 9,09 & & 18,36 & & 4,64 & & 6,55 & & 6,27 & & 44,91 & \\
\hline $\mathrm{D}$ & 12 & & 11,5 & & 17,42 & & 6,08 & & 7,17 & & 8,33 & & 50,5 & \\
\hline $\mathrm{E}$ & 13 & & 13,57 & & 16,14 & & 5,14 & & 7,43 & & 8,14 & & 50,42 & \\
\hline $\mathrm{F}$ & 6 & & 10,67 & & 17,83 & & 4,5 & & 8,5 & & 7,33 & & 48,83 & \\
\hline $\mathrm{G}$ & 10 & & 11,6 & & 16,4 & & 5 & & 6,3 & & 7 & & 46,3 & \\
\hline $\mathrm{H}$ & 8 & & 11,75 & & 17,88 & & 6,13 & & 6,38 & & 7,63 & & 49,77 & \\
\hline \multirow{2}{*}{\multicolumn{2}{|c|}{ I 1}} & & 9,31 & & 17,38 & & 4,31 & & 6 & & 7 & & 44 & \\
\hline & & \multicolumn{2}{|c|}{$\mathrm{P}=0,0023 *$} & \multicolumn{2}{|c|}{$\mathrm{p}=0,2383$} & \multicolumn{2}{|c|}{$\mathrm{p}=0,2277$} & \multicolumn{2}{|c|}{$\mathrm{p}=0,4579$} & \multicolumn{2}{|c|}{$\mathrm{p}=0,4604$} & \multicolumn{2}{|c|}{$\mathrm{p}=0,06$} & \\
\hline
\end{tabular}

NOTA: Pontuação parcial (SE - Escala; E - Escore); Turma (n-Número de Participantes); Metas Motivacionais (B - Baixa; M - Média; A - Alta).

Fonte: Elaboração própria.

Ao analisar a Tabela 3, pode-se perceber que, assim como no Estado Motivacional dos alunos, também não houve diferença significativa entre as turmas quanto à Meta Motivacional (Kruskal-Wallis, p=0,06). Todas as turmas pontuaram médio para Metas Motivacionais. Entretanto houve variação significativa na subescala Estrutura de meta para desempenho em sala de aula $(p=0,0023)$ quando submetida ao Test Kruskal-Wallis. 
Para verificar se havia variação estatisticamente significativa entre as turmas, aplicou-se Teste de Tukey, que indicou o seguinte dado: variação entre as turmas B e E $(p=0,0032), C$ e $E(p=0,0118)$ e E e I ( $p=0,0202)$. Percebe-se que as professoras das turmas B $(8,58)$, C $(9,09)$ e I $(9,31)$ fizeram menos uso de Estruturas de Meta para Desempenho em sala e a maior frequência para essa subcategoria pertence à turma $\mathrm{E}$ da professora Elizabeth Bishop (13,57), que foi também a professora que menos fez uso das Estruturas de Metas Para Competência em sala de aula.

\section{Discussão e considerações finais}

Considerando a influência das emoções no engajamento do aluno durante as aulas, tão bem descrito por Bzuneck, Megliato e Rufini (2013), partiu-se para a análise dos dados obtidos no presente estudo. Constata-se que as emoções negativas tenham sido vivenciadas nas turmas cujo escore para ansiedade foi maior, ou seja, a turma D da professora Elizabeth Bishop $(8,75)$. Nesse sentido, ao consequenciar negativamente os comportamentos dos alunos, criticando os erros ou não enaltecendo as conquistas, a atitude da professora pode ter eliciado respostas de ansiedade nos alunos, o que por sua vez comprometeu o desempenho acadêmico global que foi relatado pelos próprios alunos (SKINNER, 1991). Por outro lado, a classe de comportamento incentivar o aluno a tentar uma resposta, sem se preocupar com haver uma resposta correta esteja intimamente relacionada à liberdade de errar dada pelas professoras Emily Dickinson e Anne Sexton. Ao sequenciar desta forma os comportamentos exploratórios emitidos pelos alunos, tais professoras indiretamente passaram a mensagem de que o mais importante era expressar-se. O acolhimento que seguia as tentativas de verbalização por parte dos alunos, constituiu importante oportunidade para o aprimoramento das respostas dos mesmos, o que além de incrementar as habilidades orais deles, contribuiu para que em tal turma fossem verificados os mais baixos escores para ansiedade. Skinner (1991) nos mostra como um comportamento seguido de reforçamento positivo tende a ser repetido e gera sensação de bem estar, o que é compatível com o que foi encontrado no presente estudo.

É provável que uma maior ênfase dada à competência do aprendiz o ajude a sentirse mais confortável para participar durante as atividades propostas. Nesse sentido, escolhas são geralmente dadas por professores que fazem uso de metas para competência em sala, que, por conseguinte oferecem uma gama maior de atividades que promovem o desenvolvimento de habilidades e a autonomia do aprendiz (SKINNER; 
ZIMMER-GEMBECK, 2011). As professoras Emily Dickinson e Anne Sexton proporcionaram tal ênfase quando forneceram estratégias adequadas aos alunos incentivando-os a completar as atividades sem se preocuparem quanto às respostas exatas dadas por eles.

Em pesquisa sobre práticas motivacionais de professores e a motivação do aprendiz (GUILLOTEUX; DORNEY, 2008), comprovou-se que os alunos com menor nível motivacional eram aqueles cujas professoras selecionavam erroneamente os materiais a serem utilizados, apresentavam instruções pouco claras, não apresentavam atividades desafiadoras e demonstravam enfatizar mais a forma do que a função comunicativa da língua. Quanto aos alunos com níveis motivacionais mais elevados, o mesmo estudo apontou que suas professoras tornavam o ambiente de sala de aula agradável, apresentavam um estilo democrático de interação com os alunos, a despeito do sua proficiência na língua inglesa, incentivavam os alunos a se arriscarem, eram mais tolerantes ao erro e davam mais explicações claras e interessantes (GUILLOTEUX; DORNEY, 2008). É durante o comportamento Ponte que o professor descreve verbalmente ou de forma escrita (faz na sala, ou trabalha uma lista de estratégias) o processo para solução da atividade ao mesmo tempo em que faz demonstrações e lembra aos alunos de conhecimento ou habilidades já trabalhados em sala de aula e que irá ajudá-los a completar a tarefa. Supõe-se, portanto, que o professor ao proporcionar estratégias escritas ou orais adequadas aos alunos, eleva as chances do aprendiz de completar uma atividade com sucesso. É possível também que a frequência de comportamentos de Ponte emitidos pelos professores durante as aulas, impacte diretamente no engajamento do aluno e de que quanto maior for a frequência de comportamento de Ponte, maiores serão as chances dos alunos responderem corretamente as atividades propostas em sala de aula. Todavia, fazem-se necessárias outras pesquisas para aprofundar tal suposição.

Foi possível comprovar, através deste estudo, uma nítida relação entre o envolvimento, participação e emoções vivenciadas pelo aluno em sala de aula com os comportamentos do professor de língua inglesa ao ministrar as aulas. O professor vir a identificar e compreender as classes de comportamentos por ele emitidas que facilitam ou dificultam o aprendizado do aluno, poderá ajuda-lo a refletir sobre suas ações no sentido de proporcionar atividades apropriadas e desafiadoras e que colabore para que ele se torne um verdadeiro mediador do aprendizado, contribuindo efetivamente para $\mathrm{o}$ desempenho dos alunos ao valorizar seus esforços e tentativas de acerto. 


\section{EDUCATIONAL RELATIONS: ENGLISH TEACHER BEHAVIOUR AFFECTING MOTIVATION STUDENT}

ABSTRACT: This article is part of a research developed in Curitiba (PR) among with 82 students and four teachers from a language school connected to public federal university. It was assumed that teachers' behavior, when giving classes, could influence positively or negatively on some of the students' motivational variables and on their commitment into the class. This study aimed to evaluate students' motivational state and goals and relate these elements with the way teachers conduct their classes. The data were collected through interviews, questionnaires and direct observation of behavior into the class. Statistical data analysis made with non-parametric Kruskal-Wallis and Tukey tests have indicated the following results: 1) The greater the Responsiveness of the teacher was, the greater the positive Attitudes of the student about the course and both Performance-approach and Milieu-related Goal Orientation were; 3) The more Aversive Strategies teachers used in the classroom the greater the PerformanceApproach Goal Orientation was; 3) the greater were the Demand and the Aversive Control, the more anxious students were.

KEY WORDS: English language learning. Motivation. Anxiety. Teacher-student interaction. Language school.

\section{REFERÊNCIAS}

ACEITUNO, B. L.; AMATE, P. M.; CAMPOS, M. R. Análisis de la organización del aula y metodologias usadas en la enseñanza del inglés como lengua extranjera. Revista Ibero-Americana de Estudos em Educação, Araraquara, v.7, n.2, p.78-90, 2012. Disponível em: <http://seer.fclar.unesp.br/iberoamericana/article/view/5393/4317>. Acesso em: 10 jun. 2015.

ARCHER, J.; KERR, K. A.; PIANTA, R. C. Why measure effective teaching? In: KANE, T. J.; KERR, K. A.; PIANTA, R. C. (Ed.). Designing teacher evaluation systems: new guidance from the measures of effective teaching project. San Francisco: Jossey-Bass, 2014. p.01-05.

BATISTA, A. P.; WEBER, L. N. D. Estilos de liderança de professores: aplicando o modelo de estilos parentais. Psicologia Escolar e Educacional, Maringá, v.16, n.2, p.299-307, jul. / dez. 2012. Disponível em: <http://www.scielo.br/pdf/pee/v16n2/a13v16n2.pdf>. Acesso em: 10 jun. 2015.

BZUNECK, J. A.; MEGLIATO, J. G. P.; RUFINI, S. E. Engajamento de adolescentes nas tarefas escolares de casa: uma abordagem centrada na pessoa. Psicologia Escolar e Educacional, Maringá, v.17, n.1, p.151-161, jun. 2013. Disponível em:

$<$ http://www.scielo.br/scielo.php?script=sci_arttext\&pid=S141385572013000100016\&lng=en\&nrm=iso>. Acesso em: 10 jun. 2015.

BRASIL. Ministério da Saúde. Resolução 466, de 13 de junho de 2013. Trata de pesquisas em seres humanos e atualiza a resolução 196. Conselho Nacional de Saúde, Brasília, 13 jun. 2013. Disponível em: 
<https://www.jusbrasil.com.br/diarios/55483111/dou-secao-1-13-06-2013-pg-59>. Acesso em: 18 set. 2015.

DINIZ, E; KOLLER, S. H. O afeto como um processo de desenvolvimento ecológico. Educar em Revista, Curitiba, n.36, p.65-76, abr. 2010. Disponível em: <http://educa.fcc.org.br/pdf/er/n36/n36a06.pdf>. Acesso em: 10 jun. 2013.

GUILLOTEAUX, M. J.; DORNYEI, Z. Motivating language learners: a classroomoriented investigation of the effects of motivational strategies on student motivation. Tesol Quarterly, v.42, n.1, p.55-77, 2008. Disponível em: <http://onlinelibrary.wiley.com/doi/10.1002/j.1545-7249.2008.tb00207.x/epdf>. Acesso em: 10 jun. 2015

MOURAES, R. S. de; BRITO, W. S. de; TEIXEIRA, C. R. Questões indenitárias, ecológicas e tecnológicas no cotidiano escolar. In: VI Fórum Internacional de Pedagogia - VI FIPED, v. 1, n. 3, 2014. Anais VI FIPED. Santa Maria-RS: Associação Internacional de Pesquisa em Pedagogia. Disponível em:

http://editorarealize.com.br/revistas/fiped/trabalhos/Modalidade_2datahora_24_05_201 4_14_48_47_idinscrito_223_cdaa038b410fd961df9a335dec85aa65.pdf. Acesso em: 10 jun. 2015.

\section{MOREIRA, M. B.; MEDEIROS, C. A. Princípios básicos de análise do} comportamento. Porto Alegre: Artmed, 2007.

MOREIRA, A. E. da C.; OLIVEIRA, K. L. Estratégias de ensino do professor: um levantamento exploratório. In: CONGRESSO NACIONAL DE EDUCAÇÃO, 11.; SEMINÁRIO INTERNACIONAL DE REPRESENTAÇÕES SOCIAIS, SUBJETIVIDADE E EDUCAÇÃO, 2.; SEMINÁRIO INTERNACIONAL DE SOBRE PROFISSIONALIZAÇÃO DOCENTE. FORMAÇÃO PARA MUDANÇAS NO CONTEXTO DA EDUCAÇÃO: POLÍTICAS, REPRESENTAÇÕES SOCIAIS E PRÁTICAS, 4., 2013, Curitiba. Anais... Curitiba: PUC, 2013. p.9814-9825. Disponível em: 〈http://educere.bruc.com.br/ANAIS2013/pdf/7406_4910.pdf>. Acesso em: 04 jun. 2015.

OKAGAKI, L.; STERNBERG, R. J. Parental beliefs and children's school performance. Child Development, Chicago, v.64, p.36-56, 1993.

PELLERIN, L. A. Applying Baumrind s parenting typology to high schools: toward a middle-range theory of authoritative socialization. Social Science Research, New York, v.34, p.283-303. 2005.

SILVA, A. de S. C.; RODRIGUES, D. F.; PINHEIRO NETO, J. E. Livro didático de língua inglesa: abordagens teóricas sobre as crenças de aprendizes. REVELLI: Revista de Educação, Linguagem e Literatura da UEG-Inhumas, v.2, n.2, p.82-102, out. 2010. Disponível em: <http://www.revista.ueg.br/index.php/revelli/article/viewFile/2854/1812>. Acesso em: 10 jun. 2015.

SKINNER, B. F. Questões recentes na análise do comportamento. 3.ed. Campinas: Papirus, 1991. 
Contingencies of reinforcement: a theoretical analysis. New York: AppletonCentury-Crofts, 1969.

SKINNER, E. A.; ZIMMER-GEMBECK, M. J. Perceived control, coping, and development. In: FOLKMAN, S., Oxford handbook of stress, health, and coping. Oxford: Oxford University Press, 2011. p.35-58. Disponível em:

$<$ https://www.pdx.edu/sites/www.pdx.edu.psy/files/Perceived\%20control,\%20coping,\% 20and\%20development.pdf $>$.Acesso em: 04 jun. 2014.

WENTZEL, K. R. Social-motivational processes and interpersonal relationships: Implications for understanding motivation at school. Journal of Educational Psychology, Arlington, v.91, n.1, p.76-97, 1999. 